\title{
The Sexual Division of Labor at the Sanders Site (41LR2), Lamar County, Texas
}

Diane E. Wilson

Department of Anthropology, University of Texas

Follow this and additional works at: https://scholarworks.sfasu.edu/ita

Part of the American Material Culture Commons, Archaeological Anthropology Commons, Environmental Studies Commons, Other American Studies Commons, Other Arts and Humanities Commons, Other History of Art, Architecture, and Archaeology Commons, and the United States History Commons

Tell us how this article helped you.

This Article is brought to you for free and open access by the Center for Regional Heritage Research at SFA ScholarWorks. It has been accepted for inclusion in Index of Texas Archaeology: Open Access Gray Literature from the Lone Star State by an authorized editor of SFA ScholarWorks. For more information, please contact cdsscholarworks@sfasu.edu. 


\section{The Sexual Division of Labor at the Sanders Site (41LR2), Lamar County, Texas Creative Commons License \\ (c) (1) \&}

This work is licensed under a Creative Commons Attribution-NonCommercial 4.0 International License 


\title{
THE SEXUAL DIVISION OF LABOR AT THE SANDERS SITE (41LR2), LAMAR COUNTY, TEXAS
}

\author{
Diane Wilson \\ Department of Anthropology, The University of Texas
}

\section{INTRODUCTION}

This study examined evidence of stress on human bone in order to reconstruct the sexual division of labor for the prehistoric Caddoan culture represented at the Sanders site (41LR2). Specifically, the repeated action stress seen in degenerative joint disease was quantified in order to infer culturally prescribed and habitual actions.

Overall, the division of labor at the Sanders site was somewhat unusual among agricultural societies. Males from the Sanders site had evidence of greater stress loads. In particular, agricultural activities apppear to have been participated in by all, regardless of sex. Although the Sanders site burial population was believed to be of high social status based on burial location within the mound and grave goods, degenerative joint disease was high and activities evident from patterns of stress could not be associated with a life of leisure.

\section{THE SANDERS SITE}

The Sanders site is located in the northwestern corner of Lamar County, Texas, on Bois D'Arc Creek, a tributary of the Red River. The known site consists of two mounds and a low ridge of midden located on the eastern bank of the creek.

Absolute dating within the Caddoan region has been limited and the Sanders site is no exception. The Sanders site has not been radiocarbon dated, although in general it is believed to be representative of the earlier manifestations of the Caddoan culture, and was initially placed in the Gibson aspect. Artifacts recovered from the site suggest nearly continuous use of the site up to historic times.

Excavation of the site took place in the summer of 1931 under the direction of A.T. Jackson and B.B. Gardener from the University of Texas. Jackson fully excavated Mound 1 and trenched Mound 2 and the midden area (Figure 1).

Jackson recovered some 60 individuals from two locations in Mound 1. One group was scattered over the top of the mound, whereas the other group was located on the eastern slope of the

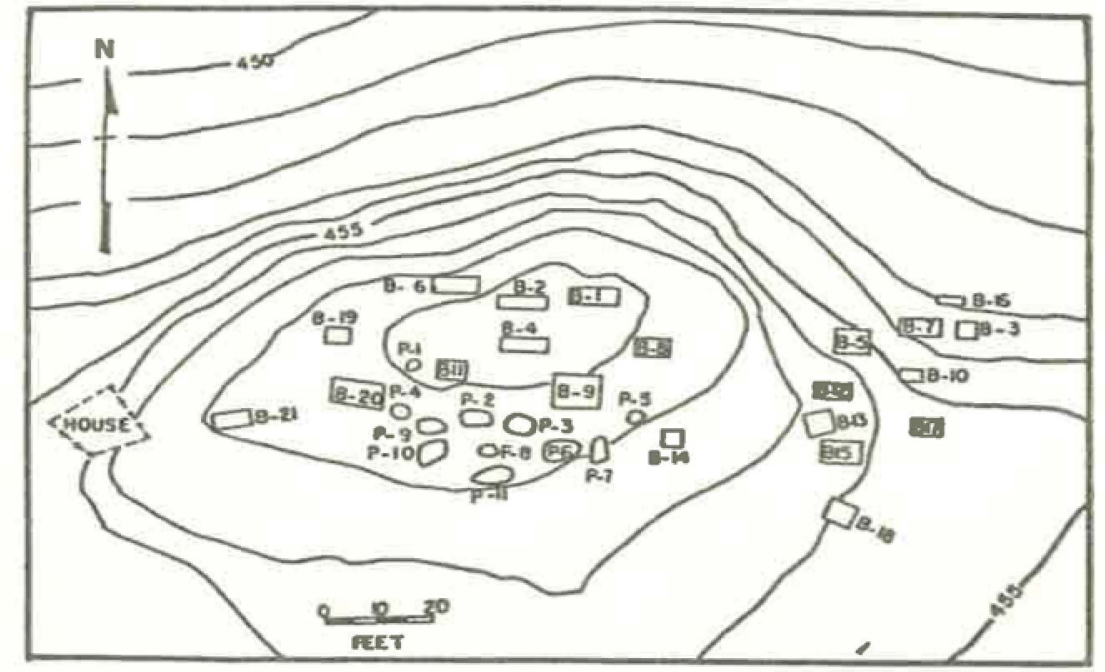

Figure 2. Mound 1 of the Sanders site with burials (B) and refuse pits (P) (from Krieger 1946:176).

mound (Figure 2). There was no difference between the two groups in burial form or offerings. Both groups contained single or multiple burials, and all individuals were extended supine or on their side. Additional burials were recovered from later excavations and pothunter backdirt. In total, 29 adult females, 25 adult males, 18 adults of indeterminate sex, and 20 children were disinterred. 


\section{DEGENERATIVE JOINT DISEASE}

Degenerative joint disease (DJD) is often termed osteoarthritis, although the latter represents a more generalized condition. DJD is caused by the wear and tear of repeated action stress on joints and by the aging process. In the joints, the first response to stress is cartilage deterioration, followed by a bone reaction. The reaction of bone is the only evidence of DJD found in the archaeological record. Bony outgrowths (termed osteophytosis and lipping) are the first and most common response to cartilage destruction (Miller 1985:392). Bone involvement, therefore, only occurs after stress in the afflicted joint when it has had some time to transpire, unless it is the result of a stress related, single event injury. Thus, reconstruction of past activities based on DJD patterns can only give an indication of the activities participated in, not the duration of time spent engaged in the activity.

Since DJD is linked to repeated actions, it has been used to reconstruct activity patterns for skeletal populations (Angel 1966; Merbs 1983; Pickering 1984; Miller 1985; Dutour 1986; Striland 1987; Bridges 1990). The term activity patterns has been taken from Merbs' (1983) study to mean habitual or culturally prescribed and sanctioned postures and practices. In this study, osteophytosis has been used to reconstruct some of the activity patterns engaged in by the Sanders burial population.

\section{METHODS}

All 55 adults curated at the Texas Archeological Research Laboratory were examined for presence of joint surfaces. Juveniles were not examined because DJD is primarily associated with repeated actions occurring over an individual's lifetime. Of these 55 adults, 43 were selected for use. Of these individuals, 14 were female (two over 50 years of age), 19 male (three over 50 years of age), and 10 were of indeterminate sex.

Bone lipping was scored from 0 to 2 , in increments of 0.25 , with 0 representing condition absent, 1 representing moderate expression, and 2 representing severe expression of the condition.

Scores were recorded on 113 distinct joint surfaces. Separate articular surfaces were examined rather than regions. For example, the ankle was not scored as one region, but the tibia articular surface for the talus, fibula articular surface for the talus, superior articular surface of the talus, and the calcaneal tuberosity were individually scored. By doing this, a more accurate account of specific activities could be gained.

The joints highly effected by preservational and recovery bias were omitted. These included carpals, tarsals, and distal phalanges. Other joint surfaces were lumped into group categories. These included ribs, and proximal phalanges of the hands.

Although the Sanders site was initially chosen for its good state of preservation, only $23 \%$ of the possible (if all individuals were complete) joint surfaces were present. Very few individuals were complete. This meant that examination of specialists within the population was impossible. Examination of individuals by sex, however, was feasible because individuals represented by specific joint surfaces could be compared with other individuals of the same sex. From this, behavioral differences between the sexes could be inferred.

\section{RESULTS}

The incidence of DJD was high among the Sanders population, with 34 (78\%) of the individuals showing evidence of affliction. In general, males were more afflicted than females, exhibiting both higher relative frequencies and higher average scores.

Activities with mean scores of 1 or more. This category contained all activity patterns with average scores for all involved joint surfaces of 1 or greater. In this way, activities that were performed most often and/or were most stressful could be inferred.

Ground clearing, planting, and soil tilling. DJD of the back was very common in the Sanders population among both sexes. This is not uncommon for agricultural populations and the patterns exhibited by both females and males were equivalent to other Mississippian related agricultural populations (Pickering 1984). Low to the ground activities such as soil preparation and ground clearing were indicated in the high levels of lower back stress seen in the lumbar and lower thoracic vertebrae. Such activities would require much bending and a stooped posture that tends to strain the lower back. 
Because the Caddo were known maize agriculturalists, lower back stress was expected. There were many artifacts in the Sanders site assemblage that indicated that ground clearing and soil tilling were taking place, such as bison scapula hoes and stone hoes.

Both lumbar and lower thoracic body scores were examined in the determination of these activities and both were well represented. Differences between the sexes were slight, indicating that both sexes participated in these activities. Both had higher scores in the lumbar region (females averaged 1.12 and males averaged 1.33; Figure 3 ), than in the lower thoracic (females averaged 1 and males averaged 0.94).

Differences between the sexes were slight in this region and may imply that females and males participated in some different activites that resulted in lower back stress. Carrying loads on the back may have accounted for these differences.

Carrying loads on the back. Osteophyte development on the sacroiliac facet has been shown to result from carrying heavy loads on the back (Trotter 1937). Males from the Sanders site had bony growths at this location, as well as high scores in their lumbar vertebrae. High scores in the sacroiliac joint suggest that weight from the load carried was directed downward through the back.

There was also evidence that females carried loads on their backs, although in a different manner than males did. Carrying loads on the back can also result in stress in the lower thoracic region of the back (Merbs 1983). In this case weight from the objects transported would be dissipated across the lower back, rather than being directed downward.

The different patterns suggest that females and males used different mechanisms to support items on their backs. This may have been a result of dissimilar objects that were normally transported.

Supporting loads on the head. Use of the head for supporting objects has resulted in cervical vertebrae spinous process bone lipping (Pickering 1984:78,97), anterior subluxation of the body (Scher 1978:97), body compression (Pickering 1984:164), locked facets (Scher 1978:97), and dorsal body compression (Merbs and Euler 1985:389). The upper cervical vertebrae were highly affected by DJD among the Sanders population.

The DJD evidence is consistent with balancing loads on the top of the head in an unaided manner. Balancing a load in this way pushes the head forward and into the chest, creating pressure and consequent osteophyte development along the anterior margins of the cervical vertebrae, as well as anterior subluxation. Osteophyte development within the Sanders female population followed this pattern. None of the individuals examined exhibited osteophyte development along the dorsal margin, as would be expected with the use of a tumpline (Merbs and Euler 1985:389). It is interesting that supporting loads on the head was not documented in either ethnohistoric or traditional accounts.

Long distance walking, running, or dancing. The posterior calcaneal tuberosity often produces a large bony outgrowth in response to long distance travel by foot (Dutour 1986:222; Figure 4). Both females and males had high scores at this locality, and both with a considerable degree of unilateral expression. Females had a more bilaterial distribution with mean scores of 2 on the right and 1.33 on the left, while males averaged 1.5 on the right and 0 on the left. The unilateral distribution seen in males may simply reflect the low number of observations on the left side (four among the males, 10 among the females).

The unilateral distribution was not found as strongly among males in other joint surfaces associated with these activities. The femur patella articular surface, femur tibia articular surface, and the patella lateral and medial articular facets all exhibited mean scores above one for both sexes (Figure 5). Results from these surfaces are all indicative of much movement at the knee, which is also associated with walking, running, and/or dancing.

The material culture from the Sanders site suggests that the members of this population may have traveled great distances to participate in exchange. The Caddo from the Sanders site may also have traveled great distances on foot to gather and/or hunt. Both females and males may have participated in these activities. Ethnohistoric accounts described women accompanying men on hunting expeditions, although only females were said to gather (Swanton 1942). 


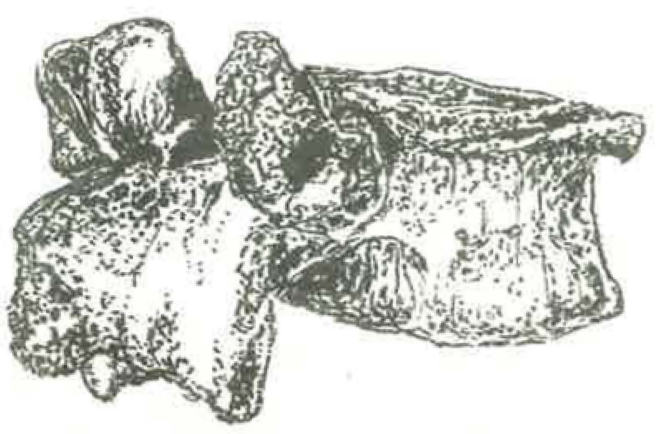

Figure 3. Lumbar vertebra from an adult male (397) with osteophyte on the superior margin of the body (drawing by Kaylee Stallings).

Unilateral distribution in the calcaneal tuberosity, particularly among the males, may have resulted from frequent or stressful par-

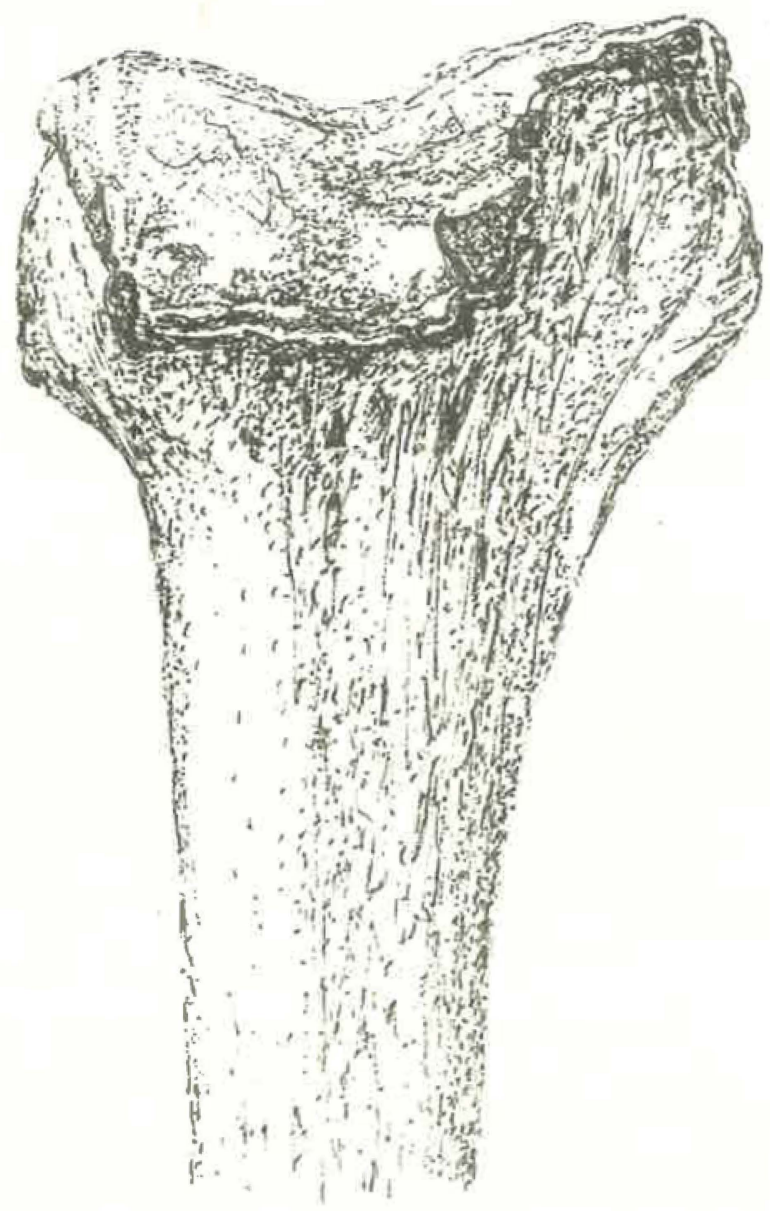

Figure 5. Left distal femur of an adult male (787). The rugged looking marginal bone growth is osteophytosis on the patella articular

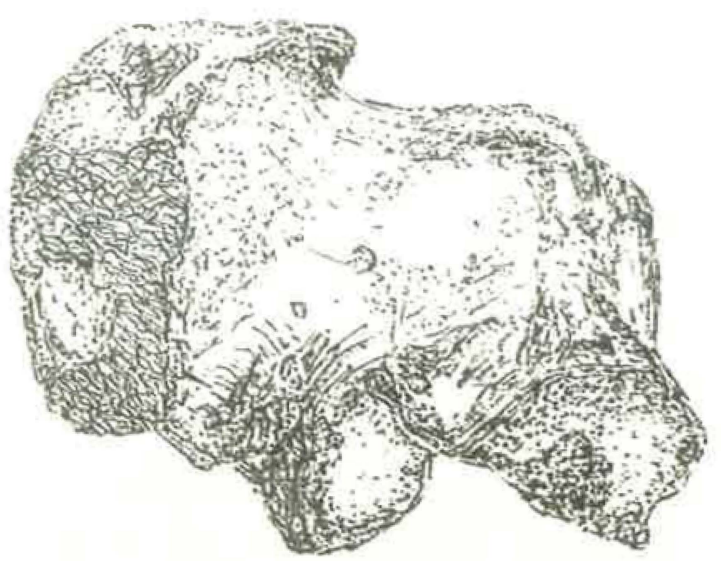

Figure 4. Adult male's (787), right calcaneus with large hook-shaped bony lip on calcaneal tuberosity. The bone in this region is normally smooth (drawing by Kaylee Stallings).

ticipation in dances that required specific foot movements balancing more weight on the right heel than on the left.

Paddling. Evidence of paddling is found in the elbow region where lipping scores are greater on the trochlea than on the capitulum of the same hand. This type of degeneration is found on both sides of the body when individuals are responsible for steering in both directions, as in paddling a canoe or rowboat. The movement is primarily flexion and extension, with rotation occurring when only one paddle is employed. This was found at the Sanders site among males with mean capitulum scores of 1.05 and mean trochlea scores of 1.19.' Oddly, scores were slightly higher on the left side.

Since the Sanders site is located on Bois D'Arc Creek, approximately three miles south of the Red River, it is likely that the river was used as an important transportation route.

Activities with mean scores of $\mathbf{0 . 7 5}$ or greater. Lowering the level of stress severity allowed the analysis of activities that were performed less often and/or were less stressful.

Sewing, basket weaving, ceramic production, and shell working. The high level of stress seen in the palmar side of the proximal phalanges of the fingers among 
females (0.94 average) suggests that females were involved in activities associated with fine finger manipulation of objects. It has been directly associated with sewing (Merbs 1983:155). Bone awls were found in burials of both sexes, and pottery disks that may have functioned as spindle whorls were recovered from the Sanders site midden. The level of stress in males was much less (0.25 average).

Ceramic manufacture and basket weaving both require extensive manipulation of small objects and the use of the fingers as tools. Both of these activities were attributed to females ethnohistorically (Swanton 1942).

Other possible activities include flint knapping and shell work, both suggested from the artifact assemblage. Further activities that would require extensive finger manipulation include husking maize, although this activity was documented traditionally as performed by both females and males (Newkumet and Meredith 1988).

Wood cutting. Osteophyte development seen in the olecranon process of the right ulna $(0.83$ mean) indicated that males may have performed wood cutting. The spicule-like growth observed on the olecranon process results from wood cutting and other activities where the arm is horizontal and the elbow flexed (Dutour 1986:222). Many stone axes were recovered from the Sanders site in the midden.

Hide scraping. DJD data indicate that scrapers were held palm-down and used in a back and forth, trough-like motion among males. This type of movement affects the distal humerus, proximal ulna, and marginal areas of the radial head (Merbs 1983:154,156; Miller 1985). The sternal and acromial facets were involved as well. Artifactual data indicate that hide scraping took place.

Carrying loads with the arms bent. Males show evidence of carrying heavy loads with their arms bent. This activity is suggested by radial tuberosity degeneration (Dutour 1986:222). However, degeneration of the radial tuberosity is the result of flexion of the elbow, hence it could also have been the result of paddling behavior.

\section{DISCUSSION AND CONCLUSION}

The activities described above are those recognized as most stressful to the Sanders burial population. The amount and frequency of DJD does not necessarily correspond to the amount of time engaged in a particular activity, although time is often a primary factor in stress induction. Many activities were not discerned here that were expected (bow and arrow use, for example). The activities not exhibited by stress markers on the bone (DJD) were therefore either not emphasized culturally or were not stressful to individuals who may have performed such activities, either rarely or often.

The activities emphasized by the Sanders population supported an agricultural subsistence economy with a great deal of travel, most likely due to participation in an extensive trade network.

Sex and status differences in food production and related activities were not as expected. Participation in these activities may seem surprising since the Sanders population has been considered an elite group. Participation in agricultural activities was found in both females and males, including planting, cultivating, ground clearing, and hoeing. However, participation in food preparation and hunting techniques was not clarified.

The patterns of DJD also may suggest a limited degree of differentiation between elite and nonelite among the Caddo. Unfortunately, a village population has not yet been analyzed for comparative purposes. Since so many individuals were afflicted, either a considerable amount of time was spent in the activities outlined, or high stress loads were endured by the population.

Stress loads were examined for females and males. It was expected that females would exhibit greater stress loads than males, as has been found in Mississippian populations (Bridges 1987; Pickering 1984). The opposite was true for the Sanders population. Males exhibited higher stress loads in terms of greater mean scores and greater relative number of articular surfaces afflicted.

The DJD evidence may suggest a ritual importance of maize agriculture. This would explain participation in activities associated with agriculture, but limited food preparation and hunting activities. Ritual importance of agriculture is also suggested by Newkumet and Meredith's (1988) depiction of men beginning each day by walking the fields of maize. 
This study was unable to determine precisely which members of the population endured greater workloads than others because the representation of articular surfaces was low. Instead, individuals were grouped by sex in order to determine a sexual division of labor. The sexual division of labor does not appear to have been strict because individuals of both sexes practiced many of the activities associated with agriculture. However, some activities not directly associated with agriculture appear to have been sex specific.

\section{ACKNOWLEDGEMENTS}

I wish to thank Dr. Thomas Hester and Dr. Darrell Creel for their encouragement throughout this project. I also wish to thank the following individuals for editorial assistance as well as help in preparing various parts of this paper: Dr. Thomas Hester, Matthew Tomaso, Kaylee Stallings, Christine Lee, and Elizabeth Andrews. In addition I would like to thank The Friends of the Texas Archeological Research Laboratory and the Potts-Sibley funds for providing me with the ability to present this data at the 1993 Caddo Conference.

\section{REFERENCES CITED}

Angel, J. Lawrence

1966 Early Skeletons from Tranquility, California. Smithsonian Contributions to Anthropology 2(1).

Bridges, Patricia S.

1987 Osteological Correlates of Weapon Use. Paper presented at the 86th Annual Meeting of the American Anthropological Association, Chicago.

1990 Skeletal Evidence of Changes in Subsistence Activities Between the Archaic and Mississippian Time Periods in Northwestern Alabama. In What Mean These Bones?, edited by Mary Lucas Powell, Patricia Bridges, and Ann Marie Wagner Mires, pp. 89-101. University of Alabama Press, Tuscaloosa.

Dutour, O.

1986 Enthesiopathies (Lesions of Muscular Insertions) as Indicators of Activities of Neolithic Saharan Populations.
American Journal of Physical Anthropology 71:221-224.

Krieger, Alex D.

1946 Culture Complexes and Chronology in Northern Texas. The University of Texas Publication 4640. Austin.

Merbs, Charles F.

1983 Patterns of Activity-Induced Pathology in a Canadian Inuit Population. National Museum of Man Mercury Series. Archaeological Survey of Canada Papers 119.

Miller, Robert J.

1985 Lateral Epicondylitis in the Prehistoric Indian Population from Nuvakwewtaqa (Chavez Pass), Arizona. In Health and Disease in the Prehistoric Southwest, edited by Charles F. Merbs and Robert J. Miller, pp. 391-399. Arizona State University Anthropological Papers 34.

Newkumet, Vynola Beaver and Howard L. Meredith

1988 Hasinai. Texas A\&M University Press. College Station.

Perttula, Timothy $\mathrm{K}$.

1993 The Caddo Nation. University of Texas Press, Austin.

Pickering, Robert Bruce

1984 Patterns of Degenerative Joint Disease in Middle Woodland, Late Woodland, and Mississippian Skeletal Series from the Lower Illinois Valley. Ph.D. dissertation, Northwestern University.

Scher, A.T.

1978 Injuries to the Cervical Spine Sustained While Carrying Loads on the Head. Paraplegia 16:94-101.

Striland, Ann

1987 Possible Correlation Between Os Acromiale and Occupation in the Burials from the Mary Rose. Proceedings of the 5th European Meeting of the Paleopathology Association, pp. 327334. Siena, Italy. 
Swanton, John R.

1942 Source Material on the History and Ethnology of the Caddo Indians. Bulletin 132. Smithsonian Institution, Bureau of American Ethnology, Washington.
Trotter, Mildred

1937 Accessory Sacro-iliac Articulations in East African Skeletons. American Journal of Physical Anthropology 22:137-142.

\section{BOOK REVIEWS}

AN ARCHEOLOGICAL SURVEY OF THE SPIRO VICINITY, LE FLORE COUNTY, OKLAHOMA. By Dennis A. Peterson, J. Daniel Rogers, Don G. Wyckoff, and Karen Dohm. Oklahoma Archeological Survey, The University of Oklahoma, Archeological Resource Survey Report 37. 87 pp., figures, tables, references cited.

This report describes the findings of a 1984 survey around the Spiro site, summarizes information from the newly located sites, and reconciles some sites with locations investigated by WPA archeological teams. For a variety of reasons, some I mention below, it will not contribute directly to the current debates of the nature and identity of the Spiro site itself or of the character of Spiroan society. It is, however, the result of a salutory effort to collect new information on this part of the Arkansas River Valley, and should be used as a springboard for more research to address the currently irresolvable differences of opinion about late prehistoric society in this region. It is also a valuable reminder that unless we act now to locate significant sites and secure either their long term preservation or new information from them, we may never have answers to our questions about this remarkable place.

Funded by a grant from the Oklahoma Office of Historic Preservation to the Oklahoma Archeological Survey, the survey goals are listed in the introductory chapter along with a brief overview of Spiro area culture history, maps of the survey area, and a useful table of previously known WPA era sites and references. The overview is a very brief summary, encapsulating essentially the published literature on Spiro area research up to the mid-1980s.

The survey was originally conceptualized as an intensive search of a six-mile radius around the Spiro site to locate and assess the integrity of all prehistoric and historic sites, and to ascertain the effects of current land use practices on them. Unrecorded Harlan phase, Spiro phase, and Ft. Coffee phase sites were to be sought, and their potential for new research was to be assessed in particular. The actual survey, carried out by Dennis Peterson in 1984, was scaled down to a block roughly two miles on a side with the Spiro site near its center. Most of this tract not included in the Spiro site proper, the Arkansas River, or areas of modern disturbance, was in pasture and forest.

Unfortunately, the survey methodology was limited to surface survey, and with the extensive ground cover and potential for alluviation in the floodplain, both the goals and the results of the project were probably significantly compromised by the absence of subsurface investigation.

Chapter 2 describes the effective natural environment of the Spiro area and the data categories collected on each site, and Chapter 3 describes the 34 sites located during the survey.

Among the information in this inventory are pertinent WPA data and citations reconciled with modern site locations, an inventory of the 1984 artifact findings, and assessments of site type and cultural affiliation. Chapter 4 concludes the body of the report with a brief summary, by Woodland period, Harlan, Spiro, and Ft. Coffee phases, and the Historic period, of the survey results. An Appendix contains an inventory of the artifacts by class/type.

The site and artifact descriptions are the heart of the report, and make this a useful volume for anyone concerned with Spiro area studies. However, the tiny artifact collections, and what I believe are premature assessments of site type and cultural affiliation weaken the concluding interpretations of Spiro area culture history. Site types are based in part on the number of houses 